\title{
LAS VIOLENCIAS HACIA LOS PROFESORES EN TRES ESCUELAS SECUNDARIAS DEL ESTADO DE JALISCO, MÉXICO
}

\author{
VIOLENCE AGAINST TEACHERS IN THREE \\ SECONDARY SCHOOLS IN THE STATE OF JALISCO, MEXICO
}

\section{Arturo Torres Mendoza*, Víctor Manuel Ponce Grima**, Ana Cecilia Valencia Aguirre****}

\section{Resumen}

En el presente artículo se planteó como objetivo general: comprender la percepción de los profesores de secundaria sobre la violencia ejercida hacia ellos de parte de sus estudiantes. Para ello, se trabajó con una metodología de carácter cualitativo mediante la aplicación de entrevistas semiestructuradas dirigidas a docentes de tres escuelas secundarias del Estado de Jalisco, México. Aunque el foco de atención estuvo dirigido a rescatar las percepciones de los profesores de las agresiones que reciben de los alumnos, dentro de los resultados se pueden destacar que los docentes perciben que son violentados por la conducta irrespetuosa de los alumnos, por el apoyo que estos reciben de sus padres, y por el contexto social del que provienen los estudiantes, aunque también son agredidos por los padres de familia. En resumen, se sienten amenazados y agredidos verbal y físicamente, no solo por los estudiantes.

* Doctor en Educación, profesor-investigador de la Universidad Pedagógica Nacional Unidad 141 Guadalajara y de la Escuela Normal Superior de Jalisco, miembro del Sistema Nacional de Investigadores (SNI) del CONACyT. Email: atm1958@outlook.es

** Doctor en Educación, profesor-investigador del Instituto Superior de Investigación y Docencia para el Magisterio (ISIDM) y del Centro Universitario de Ciencias Sociales y Humanidades de la Universidad de Guadalajara.Email: victorcanek25@hotmail.com

*** Doctora en Educación, profesora-investigadora del Centro Universitario de Ciencias Sociales y Humanidades de la Universidad de Guadalajara, miembro del Sistema Nacional de Investigadores (SNI) del CONACyT.Email: anaval_a@hotmail.com 
Palabras clave: violencia, percepción, comportamiento, escuela secundaria, docente de secundaria, estudiante de secundaria

\begin{abstract}
In this article set out as a general objective to understand the perception of secondary school teachers about the violence against them by their students. To achieve this, we worked with a qualitative methodology through the application of semi-structured interviews to teachers from three secondary schools in the State of Jalisco, Mexico. Although the focus was on rescuing teachers' perceptions of the aggressions they receive from students, the results include that teachers perceive that they are violated by the disrespectful behavior of students because ofthe support they receive from their parents; and, because of the social context from which the students come; although they are also attacked by parents. In short, they feel threatened and assaulted verbally and physically, not just by students.
\end{abstract}

Keywords: violence, perception, behavior, high schools, secondary school teachers, secondary school students

\title{
1. Introducción
}

OMO EN MÉXICO, en varios países, los profesores de secundaria enfrentan dificultades con los estudiantes y, en ocasiones, con los padres de los estudiantes. En el caso de Perú, de acuerdo con Herman Robles, especialista de Tutoría de la Gerencia Regional de Educación Arequipa, los profesores, hoy día, también son víctimas de los alumnos, ya que se les ha enseñado a los niños sus derechos, pero no sus deberes, y los profesores agredidos por los estudiantes no corrigen el comportamiento de aquellos para evitar sanciones (web del maestro CMF, 2019).

En el caso de Argentina, encontramos que el director de una escuela del municipio de Pergamino fue golpeado por un alumno de 15 años, quien se hizo acompañar por su mamá; además, se presentaron otras denuncias que refieren agresiones a una directora de la localidad 
de Tres Arroyos y a una profesora de primer grado en Villa Luzuriaga (Clarín, 2011). En España, el defensor de la Comunitat Valenciana rindió un informe que refiere el incremento de mensajes de carácter insultante e intimidatorio en grupos de WhatsApp de parte de padres y madres de alumnos dirigidos a los profesores, al tiempo que reportó a un profesor que fue dado de baja por ansiedad, después de que fue amenazado de muerte por el papá de una alumna (información.es, 2018).

Por su parte, en México y Estados Unidos, aunque ha sido tradición respetar a los profesores, eso ha cambiado actualmente. Hoy día, los estudiantes contestan, amenazan e insultan a sus profesores, incluso los llegan a golpear, razón por la cual en el Estado de Texas se promulgó la "Ley SB 2432", que tiene por objetivo proteger a los profesores, de manera que el alumno que cometa agresión verbal, maltrato físico, acose telefónicamente o por las redes a un docente será enviado a un "Programa alternativo" (Martínez, 2019).

En el contexto español, Clarc (2017) -del diario digital español "día.es"- sostiene que el representante del sindicato de profesores españoles afirmó que, "durante el curso escolar 2016-2017 se contabilizaron trescientos casos de acoso y violencia contra los profesores y maestros españoles" (párr., 1); además, Clarc (2017) agrega: "La tensión en las aulas no es nada nuevo. Lo que no se detectaba con tanta frecuencia, como ahora, es el maltrato del alumno al profesor" (párr., 3); asimismo, señala que los profesores se sienten angustiados, frustrados e imposibilitados por "vergüenza" de que son objeto de abuso por parte de sus alumnos.

En tanto, en el contexto mexicano, concretamente en el Estado de México, se está implementando un programa para fortalecer la sana convivencia entre profesores y alumnos, ya que en últimas fechas:

$\mathrm{El}$ acoso escolar parece afectar también a los profesores, quienes frecuentemente se convierten en blanco de agresiones perpetradas por sus estudiantes e incluso los padres de familia. El abuso contra los catedráticos se manifiesta frecuentemente a través de las redes sociales, aunque la violencia puede ir desde los insultos verbales hasta delitos contra la propiedad privada y agresiones físicas (González. 2017, párr., 2). 
Del mismo modo, comenta que aproximadamente el $40 \%$ de los casos de agresión contra los profesores de parte de los alumnos no son reportados por la vergüenza que ello causa, por lo que la violencia hacia los docentes no se traducen en sanciones hacia sus ejecutores; además, de acuerdo con la Encuesta del INEGI sobre la violencia hacia los docentes, los directores de las escuelas no creen que las acciones de los estudiantes en contra de sus profesores se pueda considerar como actos de violencia (González, 2017).

Ahora bien, el presente artículo se relaciona y da continuidad a estudios previos; el primero de ellos, Torres (2015a), tuvo el propósito de conocer las significaciones imaginarias sociales de los adolescentes sobre la autoridad escolar, en él, los estudiantes de secundaria señalaron, entre otras cosas, que sus docentes actúan de manera autoritaria, pero también reconocieron que ellos mismos agreden a sus profesores. El siguiente, de Torres (2015b), se planteó como objetivo central, comprender las relaciones democráticas o autoritarias que se dan entre maestros y alumnos en la escuela secundaria; por su parte, el de Torres (2016), se propuso comprender las significaciones imaginarias sociales de autoridad escolar en los adolescentes de secundaria y su vivencia en la cotidianidad escolar; al igual que el texto de Torres (2017), que se guio bajo la siguiente propuesta de comprender las significaciones imaginarias sociales que sobre el ejercicio de su autoridad construyen los profesores de secundaria.

El trabajo de Valencia y Torres (2013) centra el análisis en el concepto de autoridad y pone el acento en las interacciones adolescentesdocentes de la escuela secundaria. Finalmente, el artículo de Ponce, Torres y Ropero (2019), que introduce la categoría de relación, para entender que el proceso educativo se comprende desde lo que hacen los distintos actores inmersos en el ámbito escolar, sostiene que "en la escuela se presentan diversas agresividades individuales, institucionales y estructurales. Se trata de entramados en donde participan y sufren tanto los adolescentes como sus profesores" (p. 96); metodológicamente el estudio requirió la realización de encuestas a alumnos y profesores de 37 escuelas del área metropolitana de Guadalajara.

Como se advierte, los estudios aludidos pusieron en el centro las opiniones de los adolescentes y profesores de secundaria, con relación 
al ejercicio de autoridad docente, ya en ellos se avizoran los conflictos existentes entre docentes y alumnos. El presente artículo es puntual, dado que tratamos de develar la opinión de los profesores sobre los actos violentos que, desde su perspectiva, los estudiantes de secundaria, y otros actores sociales y educativos, ejercen sobre ellos. Para lograr el propósito de la investigación, se recogió la experiencia de varios docentes de diferentes escuelas, lo que se precisa más adelante.

Si sobre los actos autoritarios o violentos de los profesores hacia los adolescentes de secundaria se ha escrito mucho, no es así en relación con la violencia ejercida por los adolescentes y sus padres hacia los docentes; sin embargo, en fechas recientes, esto ha cambiado y se empieza a abordar el fenómeno del maltrato de los estudiantes de secundaria, y los padres de los mismos, hacia los mentores, tal como dan cuenta algunos estudios que aquí se mencionan.

Por ejemplo, Aguirre y Jacinto (2015) en su investigación "Construcción de la violencia escolar", con el apoyo de entrevistas realizadas a estudiantes de secundaria, plantean que algunos profesores llevan a cabo actos de violencia hacia los alumnos, pero también señalan que: "los alumnos no se quedan atrás a la hora de insultar a sus maestros" (p. 6). Otro estudio, que se titula "identidad docente", de Balderas y Balderas (2015), aborda la violencia institucional que se ejerce sobre los profesores, y señalan: "si los resultados de las reformas educativas no son los esperados, se [responsabiliza] directamente a los docentes" (p. 2); Caballero (2015), en el artículo titulado "El docente abandonado", afirma que los, "programas dirigidos a transformar las relaciones de los docentes con las comunidades y en especial con los padres de familia, [...] llevan a la confrontación” (p. 5), por lo que sostienen que los profesores se sienten abandonados e incomprendidos por los padres de familia, lo que -consideran- deriva en actitudes negativas de los alumnos hacia ellos.

En tanto, el texto de Jiménez y Camacho (2015) se refiere a la "Satisfacción del trabajo docente en escuelas secundarias generales" y afirman que: "el principal elemento de atención y de preocupación para los docentes de las escuelas secundarias generales son los alumnos y sus múltiples circunstancias escolares y personales”(p. 8). Rico (2015), por su parte, habla del "clima escolar" y los "procesos de convivencia 
y conflictos"; en su texto afirma que: "se encuentra que hay conductas disruptivas de los alumnos, son frecuentes la indisciplina [...] las faltas de respeto a los profesores, desobediencia y no cumplir con las normas de conducta" (p. 5); asimismo, ponen el acento en "las faltas de respeto a los profesores". Por su parte, Torres (2015a), en su trabajo sobre "Las significaciones imaginarias sociales de autoridad de una comunidad de adolescente de secundaria”, deja en evidencia que los estudiantes reconocen que, en no pocas ocasiones, agreden a los maestros verbalmente o bien les ponen sobrenombres, es decir, llevan a cabo actos que devienen en violencia hacia sus mentores. Finalmente, el trabajo de Galdames y Pezoa (2016), con el título "Violencias hacia profesores de enseñanza media en la región metropolitana de Chile", aborda "los significados atribuidos a la violencia hacia los docentes, desde la perspectiva de profesores y profesoras de escuelas secundarias municipales en la Región Metropolitana de Chile” (p. 155).

Los trabajos que se han incluido son el resultado de entrevistas a alumnos y profesores, y tienen que ver, en su conjunto, con el maltrato mutuo entre docentes y estudiantes, pero también con la violencia institucional, o la incomprensión de los padres de familia. Sin embargo, los estudios citados no mencionan agresiones físicas o insultos degradantes contra los maestros de secundaria. En el presente trabajo, se muestra una realidad distinta, dado que la violencia hacia los profesores es evidente. Probablemente, lo anterior se deba al tipo de preguntas que se les hicieron, es decir, preguntas directas sobre la violencia ejercida hacia ellos.

\section{Problema de investigación}

Como resultado del actual trabajo de investigación, hubo relación directa con estudiantes y colegas de secundaria. En este sentido, se reconoce que, en ocasiones, los docentes actúan con impaciencia, descuidando la escucha activa y sus actos devienen, no pocas veces, en autoritarios, pero también se sabe que los alumnos de secundaria son capaces de responder, ofender y agredir a sus mentores, aunque al parecer no lo hacen con todos sus profesores, pero sí con los que son 
susceptibles de victimización. En definitiva, ¿cómo o por qué ocurre este fenómeno?; ¿en qué acciones de los estudiantes se sostiene la violencia hacia los profesores?; ¿cuáles son las formas de agresión?; ¿qué otras personas violentan a los profesores en los espacios escolares? Eso lo responderán los propios mentores que participan del estudio.

En las visitas a las escuelas secundarias se da tiempo para observar las dinámicas de interacción entre docentes y alumnos, además de dialogar con algunos profesores, quienes, entre otras cosas, refieren: "no quieren trabajar, son contados los que lo hacen"; "no tienen valores"; "no se respetan entre ellos"; "los padres tienen la culpa, los tienen muy alzados"; "el otro día un chico me faltó al respeto"; "es increíble, a la profesora de inglés la hicieron llorar"; "el día de hoy empezaron a aventar bolas de papel y a silbar"; "al profesor de matemáticas un alumno le rayó la madre", o bien, "los muchachos no respetan a la autoridad”. Además, como refieren Anzaldúa y Ramírez (2016), ahora los profesores tienen el temor de ser agredidos en las redes sociales o en "la aula", un blog de cyberbullying entre estudiantes de educación básica, en que también se llevan a cabo actos de violencia virtual contra los docentes.

Pero si hasta hace poco las cadenas noticiosas informaban solo de la violencia de las autoridades escolares hacia los estudiantes, ahora también ocurre en sentido inverso, es decir, dan cuenta de las quejas de los profesores sobre agresiones recibidas por parte de los estudiantes.

Por tanto, lo que está en el centro de las preocupaciones de los docentes es la pérdida de autoridad y la creciente ola de violencia hacia ellos de parte de los estudiantes, pues consideran que algunos alumnos no acatan sus directrices, se refieren a ellos con poco respeto, los ignoran e incluso ofenden, todo ello con el apoyo o anuencia de sus mentores y quienes están al frente de la institución escolar. Sobre la base de lo planteado, se deriva la siguiente pregunta de investigación: “¿cómo perciben los docentes de secundaria la violencia ejercida hacia ellos por parte de sus estudiantes? El objetivo central se formuló de esta manera: "comprender la percepción de los profesores de secundaria de la violencia ejercida hacia ellos de parte de sus estudiantes". 


\section{Marco teórico}

La orientación teórica de este trabajo se sustenta en las ideas esgrimidas, fundamentalmente, por Foucault (1988; 2009), relativas al poder disciplinario y las violencias estructurales y/o institucionales que provocan; Deleuze (1991), quien reconoce el poder de las disciplinas, pero enfatiza la presencia, cada vez mayor, de los mecanismos de control; y, Anzaldúa y Ramírez (2016), quienes ponen el acento en la institucionalización de la violencia"y sus consecuencias en los espacios escolares.

Las violencias a las que son sometidos los profesores de secundaria, en analogía con lo que plantea Foucault (1988; 2009), ha sido un proceso en el que se ha ido imponiendo el poder disciplinario, que se corresponde con los intereses de quienes detentan el poder político y económico. Se trata de disciplinar a los docentes, de hacerles reconocer que tienen un papel específico en la estructura social y -ya que el poder produce realidades- los docentes son "normalizados" como trabajadores dentro de la estructura social y económica actual, en la cual pasan a ser objeto de examen y escrutinio, no solo de las autoridades educativa y administrativas, sino también de los padres de familia y de los estudiantes.

Por su parte, Deleuze (1991), quien coincide con Foucault sobre el poder de las "disciplinas" como "mecanismos de control" que "normalizan" y producen realidades, reconoce que el poder se ejerce "unos sobre otros" y agrega que en el régimen escolar, hoy día, están presentes: "las formas de evaluación continua y la acción de la formación permanente sobre la escuela, el abandono concomitante de toda investigación en la Universidad, la introducción de la "empresa" en todos los niveles de escolaridad (1991, p. 4). Entonces, dado que la escuela deviene en "empresa", los estudiantes y padres de familia lo hacen como "usuarios"; estos ven en los profesores "empleados" a los que se les puede exigir y no docentes con saberes disciplinares y pedagógicos que enseñan y ayudan a construir aprendizajes.

Por su parte, Anzaldúa y Ramírez (2016) -quienes comparten las ideas centrales de Foucault y Deleuze en relación al poder disciplinario, los mecanismos de control, el carácter normalizador de las disciplinas o el papel del examen- abordan el problema de la difícil situación de los 
docentes en la escuela básica, desde la perspectiva de la institucionalización de la violencia; de ahí que planteen:

La violencia escolar no se reduce en absoluto a la violencia entre pares, paradójicamente se trata de una práctica generalizada que se ejerce también entre los adultos [...] y de estos a los estudiantes y viceversa, incluso es aceptada, naturalizada e institucionalizada, forma parte inherente de las formas de la institución [...], y sus mecanismos de ejercicio del poder (Anzaldúa y Ramírez, 2016, p. 77).

Por tanto, ponen el acento en la "institucionalidad de la violencia" y están de acuerdo en que la relación de poder es parte de la "disciplina", pero cuando "el sometimiento forzoso que lleva consigo un daño físico, psicológico o moral, este ejercicio del poder se convierte en violencia" (Anzaldúa y Ramírez, 2016, p. 84). Luego, en relación con la escuela secundaria, agregan: "nadie escapa a la mirada fiscalizadora del otro, aunque sin duda alumnos y maestros son los principales objetos de atención"(p. 89). Para luego agregar y aclarar que: "los alumnos y padres de familia, se empoderan y se establece un entramado de fuerzas que derivan en complejos conflictos en torno a la disciplina y las sanciones" (p. 91); lo anterior -el empoderamiento- al amparo de la vigilancia de los órganos de la SEP y la Comisión de Derechos Humanos aseguran: "con esta multiplicidad de controles, los maestros están sometidos a diversas instancias de poder y de prácticas violentas" (p. 92).

Con relación a la violencia ejercida por los jóvenes sobre los profesores, se plantea que no se debe poner el acento en los primeros como seres irresponsables que convierten en víctimas a los segundos, ya que eso sería ver una parte del problema y no entender que el problema es de fondo y tiene que ver con las instituciones, con el clima social que posibilita la violencia que se repite en las escuelas (Anzaldúa y Ramírez, 2016, p. 97); por tanto, para estos autores el foco de la violencia está en su institucionalización y toma cuerpo en las acciones de los sujetos que conviven en el espacio escolar. 


\section{Metodología}

El sustento epistemológico y metodológico de esta investigación se basa en el paradigma interpretativo. Por lo anterior, se presenta una visión comprensiva, que permite dimensionar a los sujetos que participan de este estudio como entes que se mueven en el mundo de las subjetividades, lugar y espacio de creación y recreación social, que pueden ser comprendidos desde la interpretación de sus percepciones y deseos.

En esta investigación, no se buscó llegar a leyes generales y universales, sino comprender un fenómeno particular, sin control o predicción, mediante la interrogación permanente del propio proceso investigativo, esto es, a partir de los datos obtenidos en el trabajo de campo.

Desde la postura adoptada, se considera que lo que se hace desde el quehacer científico se relaciona con el "contexto de coexistencia humana”, por lo que las verdades son relativas; entonces, no se usó en este espacio "un discurso caracterizado como la verdad universal, con un propósito totalizador que tiende, por tanto, a ser intolerante hacia la diferencia" (Usher, 1996, p. 4).Y precisamente porque es un discurso inserto en cierto contexto, donde existen distintas ideas diferentes, los investigadores tendrán distintas perspectivas y formas de acercarse al objeto de estudio.

En consonancia con lo antes dicho, se está de acuerdo con que: "una conciencia formada hermenéuticamente debe estar dispuesta a acoger la alteridad del texto. Pero tal receptividad no supone la 'neutralidad' ni la autocensura, sino que implica la apropiación selectiva de las propias opiniones y prejuicios" (Gadamer, 1998, p. 66). No obstante lo anterior, cuando se habla de la subjetividad del investigador, ello no significa que no se haya buscado la rigurosidad, ya que aquí el interés "radica en la interpretación, el significado y la iluminación o claridad de las ideas" (Usher, 1996, p. 16). Para ello es útil trabajar con la propuesta interpretativa -esto en el plano epistemológico y metodológico- que nos ofrecen varios pensadores, entre ellos Gadamer, (1998). Cuando el autor habla de la "regla hermenéutica", considera que implica la participación del "movimiento circular de la comprensión", donde debe estar presente la "anticipación de sentido", ya que este "involucra al todo", de modo que la comprensión se devela cuando las partes que 
tienen participación del todo, definen a "ese todo".

De acuerdo con los postulados anteriores, en esta investigación se ha llegado al campo con una elaboración previa, que incluyó la construcción de una pregunta general, -que luego dio lugar a la aparición de otras- a fin de encontrar los sentidos que le dan a la violencia a la que están expuestos los profesores, como resultado de su práctica y socialización de actividades en la escuela secundaria.

Acorde con la metodología utilizada, se trabajó con entrevistas realizadas a los profesores de secundaria, titulares de las asignaturas en que los alumnos de la Escuela Normal Superior de Jalisco (ENSJ) realizaron sus prácticas, ya que pudieron tener cercanía con ellos, lo que dio confianza y facilitó la realización de las entrevistas. El foco de atención se centró en el grado en que los alumnos de secundaria manifiestan respeto o rechazo hacia la autoridad docente. Las entrevistas fueron aplicadas a docentes de diferentes escuelas: Secundaria 1, ubicada en Tlaquepaque (11 profesores); Secundaria Mixta 2, con domicilio en el municipio de Tonala (8 profesores); y, Secundaria Técnica $3^{1}$ de Amatitán (7 profesores).

Las entrevistas las aplicaron los alumnos de la ENSJ, al momento de realizar una de las jornadas de observación y práctica docente, correspondiente al ciclo escolar 2018-2019. Esta actividad se realizó bajo la supervisión de los investigadores, quienes previamente les ofrecieron un taller sobre técnicas de recogida de datos y -de manera particularsobre la que se aplicaría a los profesores entrevistados. Cabe aclarar que los nombres que se incluyen de los maestros fueron modificados para respetar su privacidad.

En cuanto a la elección de las escuelas, se seleccionó aquellas donde los alumnos, que ayudaron a aplicarlas, realizaron sus jornadas de observación y práctica docente. Se trabajó con la elaboración de entrevistas semiestructuradas y se les pidió a los estudiantes que, al llevarlas a cabo, lo hicieran de manera informal, que abordaran a los profesores con quienes ya habían establecido trato en los ratos libres, ya fuera en el receso o al término de la jornada, para lograr mayor naturalidad en sus respuestas.

${ }^{1}$ Por razones éticas se enumera a las escuelas con un número correlativo que no corresponde a su identificación real. 
Ya con las transcripciones de las respuestas a las preguntas formuladas en las entrevistas, se procedió -siguiendo a Gibbs (2012)- a revisar los textos para el análisis e interpretación de datos, de acuerdo a criterios significativos relacionados con la pregunta y objetivo general de la investigación. De este análisis, surgieron los códigos y categorías finales, que permitieron identificar las percepciones de los docentes sobre las violencias a la que son sujetos en el espacio escolar.

\section{Resultados y Discusión}

Del total de profesores entrevistados en las tres escuelas secundarias visitadas, la mayoría considera que en la escuela secundaria existe violencia hacia ellos. Se aclara que, aunque el objetivo general de la investigación tuvo que ver con la percepción de los docentes sobre la violencia ejercida hacia ellos por parte de sus estudiantes, los resultados ofrecieron hallazgos interesantes vinculados con que los docentes también se ven violentados por el respaldo que le dan a los estudiantes algunos padres de familia y ciertas autoridades escolares. La siguiente tabla es una primera aproximación a las violencias sufridas por los docentes y explica la forma en que ésta se manifiesta, así como los actores que la ejecutan y la frecuencia con que la perciben los docentes.

Tabla 1. Violencias estudiantiles

\begin{tabular}{c|l|l}
\hline \multicolumn{1}{c|}{ Actor } & \multicolumn{1}{|c}{ Percepción del origen de la violencia } & $\begin{array}{l}\text { Frecuencia con que } \\
\text { es percibida }\end{array}$ \\
\hline Estudiantes & $\begin{array}{l}\text { Violencia por la conducta irrespetuosa y agresiva } \\
\text { de los adolescentes: } \\
\text { a) relacionada con la actitud de respaldo de los } \\
\text { padres y/o autoridades escolares; b) relacionada } \\
\text { con el contexto social de origen del estudiante; } \\
\text { c) resultado del contexto familiar con uso de } \\
\text { lenguaje peyorativo; y d) resultado de autorida- } \\
\text { des escolares que promueven derechos, pero no } \\
\text { obligaciones. }\end{array}$ & $\begin{array}{l}\text { Reiterada por gran } \\
\text { estudiantes. }\end{array}$ \\
\hline
\end{tabular}

Fuente: construcción propia con base en los datos recabados. 
Como resultado de la tabla anterior, producto de revisar las respuestas de los docentes, hemos hecho la siguiente agrupación: Violencia por la conducta irrespetuosa y agresiva de los adolescentes, de la que se desprende: a) violencia por el apoyo de padres y/o autoridades escolares b) violencia relacionada con el contexto social de origen c) resultado del contexto familiar con uso de lenguaje peyorativo y, d) resultado de autoridades escolares que promueven derechos, pero no obligaciones.

\section{Violencia por la conducta irrespetuosa de los adolescentes}

Los profesores, en su mayoría, perciben que los alumnos los violentan de manera reiterada, lo que según ellos se debe a su carácter irrespetuoso y rebelde; de ahí que planteen:

“estos [se refiere a los alumnos] no respetan a nadie y más si los maestros no se les imponen, aunque la verdad hay algunos maestros que si son más estrictos, pero a otros los traen como quieren" (Carmen, entrevista 17/10/2018); "no hay respeto con la mayoría de los profesores, los alumnos se quieren poner al nivel de los maestros y quieren pasar por encima de nuestra autoridad" (Lucia, entrevista 17/10/2018); "hay alumnos muy rebeldes que siempre quieren imponerse ante los profesores" (Miguel, entrevista 17/10/2018).

Se puede decir que los docentes perciben la rebeldía y falta de respeto a su autoridad como una violencia hacia ellos, que se materializa de las siguientes formas:

\section{a) Violencia por el apoyo de padres de familia y/o autoridades escolares}

Varios docentes consideran que la violencia con que se comportan los adolescentes tiene que ver con actitudes permisivas de parte de los padres y/o de las autoridades escolares, por eso sostienen:

"seguido se burlan de los maestros. Les dicen groserías y no hacen caso; cuando se les manda llamar a sus papás, nunca vienen y no creen de lo que son capaces de hacer sus hijos, hay una relación entre padre e hijo contra el docente" (Raúl,19/10/2018); “en la escuela les dan herramientas para que se vuelvan irrespetuosos con 
nosotros, les hablan de sus derechos, pero no de sus obligaciones y yo creo que ese es el mayor problema, también que los papás 'alzan' a sus hijitos y, pues estos se aprovechan y se vuelan”; (Fernando, 17/10/2018); "les dicen varios insultos fuertes [los estudiantes a los profesores], cosa que se ve a diario, no habiendo ninguna sanción por parte de la autoridad de la escuela" (Guadalupe, 17/10/2018).

Vemos que los profesores esperarían de los padres de familia y de las autoridades escolares más apoyo; es más, consideran que debe haber sanciones, sin embargo, comentan que los chicos son alentados a actuar contra ellos, lo que se puede interpretar como "violencia institucional" contra los docentes.

\section{b) Violencia relacionada con el contexto de origen}

Varios docentes consideran que los adolescentes son groseros y agresivos con ellos, pero se refieren a que el contexto donde se desarrollan es lo que lo provoca, de tal manera que, en alguna medida, los disculpan; he aquí algunos comentarios:

"Estos muchachos tienen muchos problemas con su contexto en que viven y conviven de forma que repercute en su comportamiento dentro de la escuela, haciendo que ignoren a los profesores; y lo que es aún peor, llegan momentos en que nos agreden con malas palabras" (Antonio, 17/10/18); "se sabe que los alumnos vienen de hogares disfuncionales y, por lo tanto, no tienen en sí una autoridad en casa y no se les ha inculcado el respeto" (Fernanda, 17/10/18); "traté de investigar el porqué de esa conducta y resulta que se debe a que tienen problemas en casa, (padres divorciados, viven en casa de sus abuelitos) y, por consecuencia, quieren llamar la atención. Hace dos años tuve un alumno que era muy rebelde y grosero, pero todo tenía un porqué de su comportamiento. Su papá lo golpeaba" (Carmela, 17/10/18).

Como se advierte, se justifica la actitud de los alumnos, pues reconocen que provienen de barrios y hogares con grandes dificultades; además, de acuerdo con una profesora, a uno de los chicos lo victimizaban en su hogar. 


\section{c) Resultado del contexto familiar con uso de lenguaje peyorativo}

A continuación, se presenta una queja de un profesor que habla de la violencia de un padre de familia hacia él, y de la forma grosera en que trata a su hijo y a él mismo:

"hace como dos años me tocó regañar a un niño, yo iba para el salón y vi que este chamaco iba para la cooperativa y le dije, ¡métase al salón!, y el solo me ignoró y corrió y le grité 'no sea burro, obedezca', [...], al día siguiente que vino su papá y casi me golpeaba [...], me disculpé y dije que no era mi intención hacerle sentir así, ¿pues, ya que más me quedaba?, y ya me estaba metiendo al salón cuando el señor le dice, jórale mi cabrón ya váyase a chingarle!" (Camilo, 17/10/18).

En este caso, el profesor hace énfasis en, jórale mi cabrón ya váyase a chingarle!, pues es donde se identifica el uso del lenguaje peyorativo de parte del padre y considere que no es una forma adecuada de tratar a su hijo.

d) Resultado de autoridades escolares que promueven derechos, pero no obligaciones

Una percepción constante de los profesores, que se materializa en la viñeta que enseguida se inserta, se refiere a la falta de apoyo de las autoridades escolares para promover la formación de los chicos, quienes -desde su opinión- debieran respetar a sus docentes:

“casi todos son muy groseros, si no es que todos; además aquí en la escuela les dan herramientas para que se vuelvan más irrespetuosos con nosotros, les hablan de sus derechos, pero no de sus obligaciones" (José, 17/10/18).

El profesor percibe que las autoridades escolares son corresponsables de la actitud grosera de los alumnos, pues no les enseñan sus obligaciones, entre las que se encuentra el respeto a la autoridad docente.

A continuación, se incluye la tabla 2, que muestra la forma en que se concretan las violencias estudiantiles en contra de los profesores de secundaria y la manera en que son percibidas; se incluyen: amenazas; agresiones verbales y agresiones físicas. 
Tabla 2. Forma en que se materializan y perciben las violencias estudiantiles

\begin{tabular}{l|l}
\hline Tipo & Forma en que se perciben y/o materializan \\
\hline Amenazas & Dirigidos a la integridad física y a la propiedad \\
\hline Agresiones verbales & Por el tono de voz, burlas y groserías \\
\hline Agresiones físicas & Les arrojan papeles, les escupen o les vacían un bote de basura \\
\hline
\end{tabular}

Fuente: construcción propia con base en los datos recabados.

\section{El docente amenazado}

Una de las formas en que se perciben o materializan las violencias hacia los profesores, son las amenazas, las cuales pueden paralizar la acción de los docentes o bien provocar enfrentamiento con los estudiantes; esto evidenciaron algunos profesores:

"A un maestro hace tiempo lo esperaron fuera de la escuela para amenazarlo. La dignidad nuestra, en esta escuela, -por estos jóvenes- se ve pisoteada y hundida en la miseria" (Juan, 17/10/18); "no se les puede decir nada, ni pedirles que respeten, porque a la salida de la escuela nos amenazan con armas de fuego y nos roban todas nuestras cosas. No les decimos nada por nuestra propia seguridad" (Cesar, 17/10/18); "hace poquito me topé con Guillermo, es uno de esos chavitos que se meten nomás para meter la droga aquí, y me amenazó enfrente de todo el salón sólo porque le pedí un trabajo. Y que le digo: a mí me vale si eres hijo del chapo, del papa o del presidente aquí hay reglas y o las respetas o te vas, y sí, hace poco lo corrieron" (Rocío, 17/10/18).

Con relación a este tipo de violencia, algunos profesores muestran frustración y sienten que se atenta contra su dignidad; asimismo, se manifiesta impotencia, ya que guardan silencio para evitar agresiones, en tanto que otros prefieren enfrentar a los estudiantes en los mismos términos. Merece atención observar que mencionen que hay quienes se inscriben a la escuela para distribuir drogas. 


\section{El docente agredido verbalmente}

Si antes nos referimos a las amenazas, estás están ligadas a las acciones. Sobre este punto, los profesores manifiestan la forma en que perciben las agresiones que reciben de manera verbal por parte de los estudiantes de secundaria:

"en ocasiones los jóvenes dicen groserías y se nos dirigen con voz agresiva" (Carmen, 17/10/18); "seguido se burlan de los maestros, les dicen groserías y no hacen caso" (MoTl1, 17/10/18); "casi todos son muy groseros, si no es que todos” (Gerónimo, 17/10/18); "a un niño lo suspendieron porque cometió una agresión verbal hacia un maestro diciéndole groserías y haciéndole señas en frente de él" (María, 17/10/18); "le dijeron a una maestra de inglés que su plática valía verga" (Ismael, 17/10/18); "varios de nuestros compañeros han salido agredidos no solo verbal sino físicamente” (José, 17/10/18).

En concreto, los docentes identifican las agresiones verbales de los estudiantes por la "voz" utilizada, las burlas de las que son sujetos, las groserías que soportan, tales como decir que su "plática vale verga, o las señas que les hacen, lo cual -la mayoría de las veces- deben soportar de manera estoica.

\section{El docente agredido físicamente}

El docente no sólo es amenazado o agredido verbalmente; en ocasiones, y de acuerdo a las respuestas de los maestros entrevistados, pasan de manera directa a la agresión física:

"cuando los maestros pasan los alumnos les arrojan papeles adrede, es común" (Hilda, 17/10/18); "sí, en una ocasión todos los alumnos compraron chicles de purga y se los ofrecían al maestro de matemáticas cuando pasaba a revisar los trabajos," (Arturo, 17/10/18); "en una ocasión el maestro regañó a uno de los alumnos y al terminar la clase el maestro bajaba por las escaleras y el alumno le escupió en la cabeza" (Fernanda, 17/10/16); "hubo una ocasión en la que una alumna le vació el bote de basura en 
la cabeza a uno de sus maestros" (Teresa, 17/10/18); "un niño se orinó sobre la silla de una maestra... el grupo no dijo nada, la maestra entró con un pantalón blanco entallado, le tocaban dos horas seguidas y lo primero que hizo ella fue sentarse, no se paró para nada durante las dos horas, aguantó vara" (Isaac, 17/10/18).

En este caso, se trata de faltas graves, ya que les "arrojan papeles", les dan "chicles de purga" o son agredidos de manera humillante al vaciarle el "bote de basura" en la cabeza" o "escupirle en la cabeza"; la última, quizá sea la más ofensiva, "orinar sobre la silla de la maestra". Por eso, tal como señala un profesor: "la dignidad de los maestros está por los suelos".

Foucault $(1988,2009)$ y Deleuze (1991) nos hablan del poder disciplinario que normaliza, de las relaciones de poder que se establecen entre los sujetos, de los mecanismos de control, de la escuela como empresa y de los estudiantes y padres de familia como usuarios del sistema educativo. Por su parte, Anzaldúa y Ramírez (2016) ponen el acento en la "institucionalización", "naturalización" y "aceptación" de la violencia en las escuelas secundarias y el "empoderamiento" de los estudiantes y padres de familia.

Desde el reconocimiento de los profesores entrevistados, el poder disciplinario ha hecho sus efectos sobre ellos, los ha normalizado, pues reconocen que las relaciones de poder no los favorecen, dado que los estudiantes y padres de familia, que se han empoderado y se asumen como usuarios, ejercen sus "derechos", pero no son corresponsables de las obligaciones que se desprenden de sus acciones que, muchas veces, devienen en violentas; de este modo, las violencias hacia los docentes de secundaria se pueden considerar en proceso de naturalización, aceptación y hasta institucionalización.

\section{Conclusiones}

El objetivo de la presente investigación fue comprender la percepción de los profesores de secundaria acerca de la violencia ejercida hacia ellos por parte de sus estudiantes. En el contexto actual, los profesores de secundaria se enfrentan a la violencia que sobre ellos se ejerce, de 
manera que manifiestan ansiedad, angustia y frustración. En ocasiones, reciben amenazas de muerte; sin embargo, no se atreven a defenderse, a actuar, pues les da vergüenza reconocer que no son capaces de responder a las violencias de sus estudiantes, pues tratan de evitar sanciones que, eventualmente, les puedan imponer las autoridades escolares.

En concreto, en cuanto a la violencia ejercida por los estudiantes y de acuerdo a su origen, los docentes perciben que se debe a la conducta irrespetuosa de los adolescentes; esta tiene sustento en las actitudes de aliento y permisividad de los padres de familia y las autoridades escolares; y la relacionan con el contexto social donde se desarrollan los chicos.

En cuanto a la forma en que se materializan y perciben las violencias estudiantiles, se expresan en las siguientes categorías: amenazas, que están dirigidas a la integridad física y a las propiedades; agresiones verbales, que se manifiestan por el tono de voz, burlas y groserías; $y$, agresiones físicas, cuando les arrojan papeles, les escupen o vacían un bote de basura en la cabeza.

Asimismo, se reitera que, aunque desde la pregunta de investigación y el objetivo general se hace referencia a las violencias de los estudiantes hacia los docentes, las entrevistas dejaron ver que los estudiantes son apoyados por los padres de familia y las autoridades escolares, por lo que se puede deducir que se trata de un fenómeno de carácter estructural, por tanto, de una suerte de violencia institucional, lo que requiere de un estudio más amplio para futuras investigaciones.

\section{Referencias}

Anzaldúa, R. y Ramírez, B. (2016). Institucionalización de la violencia. En Claudio Carrillo, Las violencias en los entornos escolares (pp. 76-103). Guadalajara: Universidad de Guadalajara.

Aguirre, D. y Jacinto, M. (2015). Construcción de la violencia escolar: influencias, causas y posibles alternativas. Memoria electrónica del XIII Congreso Nacional de Investigación Educativa (p. 1-9). Chihuahua, México. Recuperado de: http://www.comie.org.mx/congreso/memoriaelectronica/v13/ doc/2227.pdf 
Balderas, I. y Balderas, M. (2015). Los estudios de identidad docente en el marco de las reformas educativas. Memoria electrónica del XIII Congreso Nacional de Investigación Educativa (p. 1-12). Chihuahua, México. Recuperado de: http://www.comie.org.mx/congreso/memoriaelectronica/v13/doc/1856.pdf

Caballero, J. (2015). El docente abandonado. Memoria electrónica del XIII Congreso Nacional de Investigación Educativa (p.1-9). Chihuahua, México. Recuperado de: http://www.comie.org.mx/congreso/memoriaelectronica/v13/doc/1465.pdf

Clarc, J. (14 de diciembre de 2017). El maltrato hacia los profesores. El día.es. Recuperado de: https://eldia.es/criterios/2017-12-14/3-maltrato-profesores.htm

Clarín (30 de septiembre 2011) Más casos de violencia contra los docentes en la provincia. Clarín.com Recuperado de: https://www.clarin.com/educacion/casos-violencia-docentes-Provincia_0_SJd7hdnnPQx.html

Deleuze, G. (1991). “Posdata sobre las sociedades de control”. En Christian Ferrer (Comp.) El lenguaje literario, To 2, Ed. Nordan, Montevideo. Recuperado de: http://theomai.unq.edu.ar/conflictos_sociales/Deleuze_Postdata_sociedad_control.pdf

Foucault, M. (2009). Vigilar y castigar. Nacimiento de la prisión. México: Siglo Veintiuno Editores.

Foucault, M. (1988). El sujeto y el poder. En H. Dreyfus y P. Rabinow. Michael Foucault: Más allá del estructuralismo y la hermenéutica. México: UNAM

Gadamer, G. (1998). Verdad y método II. Salamanca: Sígueme.

Galdames, A. y Pezoa, C. (2016). Violencias hacia profesores de Enseñanza Media en la Región Metropolitana de Chile, Rumbos TS. Un espacio crítico para la reflexión en Ciencias Sociales, XI(14), 155-172. Recuperado de: $\mathrm{http} / / /$ revistafacso.ucentral.cl/index.php/rumbos/article/view/406/370

Gibbs, G. (2012). El análisis de datos cualitativos en investigación cualitativa. Madrid: Morata.

González, C. (18 de junio2017). Crecen ataques de alumnos a docentes. Milenio. Recuperado de: http://www.milenio.com/estados/crecen-ataques-dealumnos-a-docentes 
Jiménez, M. y Camacho, M. (2015). Satisfacción con el trabajo docente en escuelas secundarias generales. Un estudio de trayectorias profesionales. Memoria electrónica del XIII Congreso Nacional de Investigación Educativa (p. 1-10). Chihuahua, México. Recuperado de: http://www.comie. org.mx/congreso/memoriaelectronica/v13/doc/0086.pdf

Martínez, A. (05 de agosto 2019). A lo que hemos llegado. El Mañana. Recuperado de: https://elmanana.com.mx/opiniones/a-lo-que-hemos-llegado/

Noticias de Alicante (22 de noviembre2018). Crece el acoso a los docentes a través de los grupos de WhatsApp de los padres. Información.es. Recuperado de: https://www.diarioinformacion.com/alicante/2018/11/22/crece -acoso-docentes-traves-grupos/2089278.html.

Ponce, V. Torres, A. y Ropero, P. (2019). La convivencia en las escuelas secundarias de la periferia de Guadalajara. Experiencia formativa y relacional.RevistaEduc@rnos.Año 8 (32), 93-126.

Rico, M. (2015). El clima escolar: una mirada a los procesos de convivencia y conflictos. Memoria electrónica del XIII Congreso Nacional de Investigación Educativa (p. 1-10). Chihuahua, México.

Torres, A. (2016). Autoridades escolares y adolescentes de secundaria: relaciones que en ocasiones devienen en violentas. En Claudio Carrillo. Las violencias en los entornos escolares (pp. 212-228). Guadalajara: Universidad de Guadalajara.

Torres, A. (2017). Docencia violentada. Las significaciones imaginarias sociales del ejercicio de autoridad de los profesores de secundaria. Memoria electrónica del XIV Congreso de Investigación Educativa del COMIE (p. 1-11). San Luis Potosí, México.Recuperado de: http://www.comie.org.mx/congreso/memoriaelectronica/v14/doc/1211.pdf

Torres, A. (2015a). Las significaciones imaginarias sociales de autoridad de una comunidad de adolescentes de secundaria. Memoria Electrónica del XIII Congreso Nacional de Investigación Educativa del COMIE (p.1-11). Chihuahua, México. Recuperedo de: http://www.comie.org.mx/congreso/memoriaelectronica/v13/doc/0038.pdf

Torres, A. (2015b). Prácticas democráticas o autoritarias en la escuela secundaria. Memoria Electrónica del XIII Congreso Nacional de Investigación Educativa del COMIE (p. 1-10). Chihuahua, México. Recuperado de: http:// www.comie.org.mx/congreso/memoriaelectronica/v13/doc/0708.pdf 
Usher, R. (1996). Una crítica de los supuestos epistemológicos que subyacen en la investigación educativa. En D. Scott y R. Usher (Eds.), Comprendiendo la investigación educativa (p. 9-32). New York: Editorial Toutledge. Valencia, A. y Torres, A. (2013). El concepto de autoridad, un análisis desde distintas miradas conceptuales. Revista Diálogos Pedagógicos. Año XI, 22, 45-63.

WEB DEL MAESTRO CMF. (7/06/2019). Los docentes también son maltratados por los alumnos. Recuperado de: http://webdelmaestrocmf.com/ porta1/los-docentes-tambien-son-maltratados-por-alumnos/

Recibido: 13.11.2019 Aceptado: 06.02.2020 